\title{
sciendo
}

\author{
EWELINA MAZUR ${ }^{1}$, BEATA DOBROWOLSKA² ${ }^{2}$ RENATA RABIASZ ${ }^{3}$, ANNA PILEWSKA-KOZAK $^{4}$
}

\section{Opinions of nursing and medical students before the end of their university education on their preparation for work with the dying patient}

\begin{abstract}
Introduction. Well-implemented, holistic care of the dying patient requires appropriate qualifications from the medical personnel.

Aim. The aim of the study was to collect the opinions of nursing and medical students before the end of their professional education on their preparation to provide care to the dying patient.

Material and methods. The survey was carried out in a group of 213 medical and nursing students during their final year of professional education.

Results. Students were unable to clearly express their opinion on their preparation to provide care to patients at the end of their lives $(87 ; 40.8 \%)$. Nursing students were more likely to perceive themselves as prepared for such care $-30(26.7 \%)$ than medical students $-11(10.9 \%)$. Statistically significant correlation was observed. A large group of the students $(92 ; 43.2 \%)$ had never been present at the scene of a patient's death during clinical classes. The majority of the respondents chose 'definitely not' (59; 27.7\%) and 'rather not' $(53 ; 24.9 \%)$ answers when asked if their university education had prepared them for work with patients at the end of their lives. Students considered their knowledge to be lacking mostly in areas such as coping with their own emotions in the face of a patient's death $(137 ; 64.3 \%)$; communicating with a dying person $(119 ; 55.9 \%)$; providing care to the patient's family $(154 ; 72.3 \%)$; cooperating with the patient's family $(125 ; 58.7 \%)$.

Conclusions. Students of both majors are not certain about the level of their preparation to provide care to people at the end of their lives, nor about the extent to which their university education had introduced them to the specificity of care of a dying patient. The medical students were observed to exhibit higher statistical significance as compared to the nursing students. The university curriculum prepared the students to take care of the dying patient's biological sphere, but did not prepare them to assume a holistic approach to care of the patient and his family.
\end{abstract}

Keywords: end-of-life care, nursing students, medical students, professional education.

DOI: $10.2478 /$ pjph-2018-0024

\section{INTRODUCTION}

End-of-life care (EOL) forms an essential part of medical care that provides patients at the end of their lives with symptomatic treatment based on continuous observation and diagnosis of their condition, including alleviation of suffering and comfort in all areas of their personality as well as emphatic communication with the patient and his or her family. All these activities are carried out in an atmosphere of respect for the dignity of the dying person and his/her relatives [1]. The purpose of EOL is to enable the patient to pass away with dignity by creating conditions for what is referred to as "good death", at the right time and without any attempts to "restore" life by force or aggressively prolong the patient's agony [2].

In view of the ageing population, but also the trend observed in recent decades, i.e. the majority of patients dying in medical care institutions rather than at home, there is a substantial need for proper education of future physicians and nurses on ho- listic, multi-faceted end-of-life care $[3,4]$. The complexity of EOL requires from those working with dying persons not only appropriate knowledge and skills, but also deep empathy and a mature attitude towards his/her own and someone else's death. Regrettably, the results of research carried out globally and in Poland have shown that nursing and medical students do not feel prepared to provide care to patients at the end of their lives [5-7], and it is only after they start career that they acquire knowledge in this respect - this unfortunately acts against the quality of care [4].

\section{AIM}

The aim of the research study was to get to know the opinions of nursing and medical students just before the end of their professional education on their preparation to provide care to the dying patient.

\footnotetext{
${ }^{1}$ Department of Infectious Diseases for Children, St John of God Independent Public Provincial Hospital in Lublin, Poland

2 Department of Basic Nursing and Medical Teaching, Faculty of Health Sciences, Medical University of Lublin, Poland

${ }^{3}$ Department of Nursing, Institute of Health and Economy, Stanisław Pigoń State Higher Vocational School in Krosno, Poland

${ }^{4}$ Chair and Department of Gynaecology and Gynaecological Endocrinology, Faculty of Health Sciences, Medical University of Lublin, Poland
} 


\section{MATERIAL AND METHODS}

The study with the use of the diagnostic survey method and a questionnaire was conducted online at www.ankietka.pl and on the basis of questionnaires distributed among the students. The questionnaires were distributed among final-year students of nursing (first degree studies) and medical faculties at the one medical university located in Eastern Poland in person and via the Facebook social networking site (www.facebook.pl). The study was conducted at the end of the academic year, just before graduation. The study was carried out in accordance with the provisions of the Declaration of Helsinki. Participation in the study was voluntary and anonymous. The purpose of the study was specified in a separate paragraph at the beginning of the questionnaire. Upon starting to fill in the questionnaires, the students gave their consent to participate in the study and could withdraw at any time. A total of 213 correctly completed questionnaires were returned: 112 from the nursing students and 101 from the medical students.

The study uses a modified version of the survey questionnaire developed by Dobrowolska et al. [8,9]. The questionnaire form included 24 thematic questions and the so-called demographic questions. Thematic questions concerned the evaluation of students' preparation to provide care to the dying patient; the evaluation of diploma education in the field of endof-life patient care; students' interest in working with patients at the end of their lives; and students' interest in participating in training courses on the care of the dying patient. For the purposes of this paper, selected data regarding students' opinions on their preparation for work with dying patients were used.

A statistical analysis of the collected data was carried out using the IBM SPSS Statistic software. It employed the T-test for dependent samples to calculate differences between the compared groups in the case of quantitative variables. The variables measured on the ordinal scale were subjected to the Mann-Whitney $\mathrm{U}$ test. The correlation between the qualitative variables was analysed using the chi-squared test. The significance level adopted in the study was $\mathrm{p}<0.05$.

\section{RESULTS}

The number of 213 students (100\%) took part in the study, including $112(52.6 \%)$ nursing students and $101(47.4 \%)$ medical students. The group comprised 174 women $(81.7 \%)$ and 39 men (18.3\%). The age of the respondents ranged from 20 to 33 years.

The results showed that the largest group in the study comprised students who were unable to clearly assess their preparation to provide care to patients at the end of their lives (87; $40.8 \%)$. When it comes to $10(4.7 \%)$ respondents, they considered themselves 'definitely' prepared and 31 (14.6\%) "rather" prepared for work with dying patients. 'Rather not' and 'definitely not' as regards above mentioned preparation, were the answers chosen by $49(23 \%)$ and $36(16.9 \%)$ students, respectively.

As far as the field of study is concerned, the nursing students were more likely to perceive themselves as prepared for such care - $30(26.7 \%)$, as compared to medical students $-11(10.9 \%)$. No definite answer could be provided by $35(34.7 \%)$ future physicians and $52(46.4 \%)$ future nurses. Detailed data are presented in Table 1.
TABLE 1. Students' self-assessment of their preparation to provide care to dying patients, depending on the field of study.

\begin{tabular}{lcccc}
\hline \multirow{2}{*}{ Students' answers } & \multicolumn{2}{c}{ Nursing students } & \multicolumn{2}{c}{ Medical students } \\
\cline { 2 - 5 } & $\mathbf{n}$ & $\mathbf{\%}$ & $\mathbf{N}$ & $\mathbf{\%}$ \\
\hline Definitely yes & 8 & 7.1 & 2 & 2.0 \\
\hline Rather yes & 22 & 19.6 & 9 & 8.9 \\
\hline Difficult to say & 52 & 46.4 & 35 & 34.7 \\
\hline Rather not & 17 & 15.2 & 32 & 31.7 \\
\hline Definitely not & 13 & 11.6 & 23 & 22.8 \\
\hline In total & 112 & 100 & 101 & 100 \\
\hline
\end{tabular}

A large group of the surveyed students $(92 ; 43.2 \%)$ had never been present at the scene of a patient's death during practical classes, as part of their university curricula; some of them did this "very rarely" $-83(39 \%)$ - or "rarely" - $31(14.6 \%)$. Five $(2.3 \%)$ and two $(0.9 \%)$ students, respectively, stated that they had been present at the scene of a patient's death "often" and "very often". The frequency of students' experience of being present at the scene of a patient's death during their clinical education, depending on the field of study, is presented in Table 2.

TABLE 2. The experience of being present at the scene of a patient's death by students during their clinical education, depending on the field of study.

\begin{tabular}{lcccc}
\hline \multirow{2}{*}{ Frequency } & \multicolumn{2}{c}{ Nursing students } & \multicolumn{2}{c}{ Medical students } \\
\cline { 2 - 5 } & $\mathbf{n}$ & $\mathbf{\%}$ & $\mathbf{N}$ & $\mathbf{\%}$ \\
\hline Never & 39 & 34.8 & 53 & 52.5 \\
\hline Very rarely & 47 & 42.0 & 36 & 35.6 \\
\hline Rarely & 21 & 18.8 & 10 & 9.9 \\
\hline Often & 5 & 4.5 & 0 & 0.0 \\
\hline Very often & 0 & 0.0 & 2 & 2.0 \\
\hline In total & 112 & 100 & 101 & 100 \\
\hline
\end{tabular}

The majority of the respondents chose the answer 'definitely not' $(59 ; 27.7 \%)$ and 'rather not' $(53 ; 24.9 \%)$ when asked if their university education had prepared them for work with patients at the end of their lives. On the other hand, 9 students (4.2\%) stated that their education had 'definitely' prepared them to provide care to dying patients and $45(21.1 \%)$ felt that it had 'rather' prepared them. 47 (22.1\%) of the respondents had no view on this matter. The vast majority of the medical students $(73 ; 72.3 \%)$ were of the opinion that their studies had not prepared them to work with people at the end of their lives; 43 respondents from this group (42.6\%) chose the 'definitely not' option. The number of 39 nursing students $(34.8 \%)$ considered their diploma education to be unsatisfactory as regards preparation to provide end-of-life care; $16(14.3 \%)$ respondents from this group chose the "definitely not" option (Table 3).

TABLE 3. Students' opinions on their university preparation to provide care to dying patients, depending on the field of study.

\begin{tabular}{lcccc}
\hline \multirow{2}{*}{ Students' answers } & \multicolumn{2}{c}{ Nursing students } & \multicolumn{2}{c}{ Medical students } \\
\cline { 2 - 5 } & $\mathbf{n}$ & $\mathbf{\%}$ & $\mathbf{N}$ & $\mathbf{\%}$ \\
\hline Definitely yes & 6 & 5.4 & 3 & 3.0 \\
\hline Rather yes & 32 & 28.6 & 13 & 12.9 \\
\hline Difficult to say & 35 & 31.3 & 12 & 11.9 \\
\hline Rather not & 23 & 20.5 & 30 & 29.7 \\
\hline Definitely not & 16 & 14.3 & 43 & 42.6 \\
\hline In total & 112 & 100 & 101 & 100 \\
\hline
\end{tabular}


A statistically significant correlation was found between the field of study and the students' self-perceived preparation to provide care to patients at the end of their lives $(p<0.001)$. The medical students were more likely to consider themselves unprepared for work with such patients (Table 4).

TABLE 4. Correlation between the field of study and the students' self-perceived preparation to provide care to dying patients.

\begin{tabular}{lcccc}
\hline Students & M & SD & $\begin{array}{c}\text { T-test for } \\
\text { dependent } \\
\text { samples }\end{array}$ \\
\cline { 1 - 3 } Medical & 3.6436 & 0.99583 & & 4.256 \\
\cline { 1 - 2 } Nursing & 3.0446 & 1.05171 & $\mathrm{p}<0.001$ \\
\hline
\end{tabular}

A substantial number of the surveyed students $(87 ; 40.8 \%)$ stated that the classes during their diploma education had not introduced them to the specifics of care of the dying patient. A large group of the respondents $(76 ; 35.7 \%)$ found it difficult to provide a clear answer on this issue. More medical students $(60 ; 59.4 \%)$ than nursing students $(27 ; 24.1 \%)$ believed that their studies did not introduce them to the specifics of caring for a dying person. Detailed data are presented in Table 5.

TABLE 5. Introduction to the specifics of care for a dying patient in the course of professional education - students' opinions depending on the field of study.

\begin{tabular}{lcccc}
\hline \multirow{2}{*}{ Students' answers } & \multicolumn{2}{c}{ Nursing students } & \multicolumn{2}{c}{ Medical students } \\
\cline { 2 - 5 } & $\mathbf{n}$ & $\mathbf{\%}$ & $\mathbf{n}$ & $\mathbf{\%}$ \\
\hline Definitely yes & 11 & 9.8 & 1 & 1.0 \\
\hline Rather yes & 25 & 22.3 & 13 & 12.9 \\
\hline Difficult to say & 49 & 43.8 & 27 & 26.7 \\
\hline Rather not & 19 & 17.0 & 36 & 35.6 \\
\hline Definitely not & 8 & 7.1 & 24 & 23.8 \\
\hline In total & 112 & 100 & 101 & 100 \\
\hline
\end{tabular}

The majority of students $(174 ; 81.7 \%)$ said that their studies had prepared them to take care of the patient's biological sphere at the end of his/her life. Slightly more than half of the respondents $(110 ; 51.6 \%)$ stated that the educational material presented during their studies had also prepared them to tackle with the moral aspects of dying and death; organisational measures as regards creating decent dying conditions (119; $55.9 \%$ ); and cooperation within the therapeutic team in the process of caring for dying patients $(114 ; 53.5 \%)$. The following areas of their university education were considered most deficient by the respondents: preparation to deal with one's own emotions in the face of a patient's death $(137 ; 64.3 \%)$; developing the ability to communicate with a dying patient (119; $55.9 \%)$; providing care to the patient's family $(154 ; 72.3 \%)$; and learning how to cooperate with the patient's family (125; $58.7 \%$ ). Furthermore, the respondents believed their education had not prepared them to take proper care of the spiritual (135; $63.4 \%)$ and mental spheres $(113 ; 53 \%)$ of a dying patient.

Discrepancies were observed between the fields of study and opinions on the scope of thematic education concerning the care of a dying patient. Among the medical students, $80.2 \%(n=81)$ of the respondents expressed negative opinions on their training in the provision of mental care to dying persons, while according to $71.4 \%(n=80)$ of the respondents from the nursing faculty their studies had prepared them for such care. A similar situation occurred in the case of spiritual care. A positive assessment was given by $62.5 \%(n=70)$ of the nursing students, while $92 \%(n=92)$ of the medical students expressed negative opinions. Their education had prepared them to communicate with dying patients in the opinion of $66.1 \%(n=74)$ of the respondents from the nursing faculty; a contrary view was expressed by $80.2 \%(n=81)$ of the respondents from the medical faculty. The majority, i.e. $90.1 \%$ $(n=91)$, of the medical students stated that their studies had not provided them with preparation to cope with their own emotions while caring for patients at the end of their lives; $58.9 \%(\mathrm{n}=66)$ of the respondents from the nursing faculty said that they had acquired such skills during their studies. As regards organisational skills in creating decent dying conditions, preparation had been received by $80.4 \%(n=90)$ of the nursing students and $28.7 \%(\mathrm{n}=29)$ of the medical students. When it comes to $75.9 \%(n=85)$ of the nursing students and $28.7 \%$ $(n=29)$ of the medical students, they reported that during their university education they had acquired competences to engage in cooperation within a therapeutic team. A similar discrepancy was also observed with regard to the moral aspects of dying and death: $80.4 \%(n=90)$ of the nursing students and $19.2 \%(n=20)$ of the medical students had gained knowledge of the subject during their university education.

\section{DISCUSSION}

Research reports show that not only nursing and medical students, but also professionally active nurses and physicians do not consider themselves adequately prepared to provide care to dying patients. This is evidenced by opinions shared by physicians and nurses as well as by patients and their families [4,6,8-11]. One must realise that the process of dying and death is special and, at the same time, difficult for the patients and their families on the one hand, but, on the other hand, for the medical staff as well. Hence, it is so important for physicians and nurses to be adequately prepared in this respect so that they can provide the patient and his/her family with high-quality care, as well as take care of themselves and cope with their emotions in the face of the patient's death [12]. The results of own research have shown that students just before receiving their physician's and nurse's diplomas are not confident about their preparation for work with dying patients $(40.8 \%)$ or they have a negative opinion of this preparation (39.9\%). Statistically, this is more common among the medical than the nursing students $(p<0.001)$. Additionally, the respondents were unable to clearly state whether their university curricula had accurately introduced them to the specifics of end-of-life care: $40.8 \%$ of the students provided negative answers and $35.7 \%$ found it difficult to say.

This might be due to the fact that students are very rarely exposed to death during their professional education. In this study, students admitted that they had never (43.2\%) or rarely (19\%) experienced being present at the scene of a patient's death during their clinical classes. This has also been pointed out in research by other authors [10], who indicated the need to look for educational alternatives in this area, e.g. in the form of medical simulation. The effectiveness of medical simulation in the development of social competences required in the care of the dying has been indicated $[4,13]$.

The surveyed students, especially those from the medical faculty, indicated that their professional training programme had not prepared them to take care of the mental and spiritual spheres of patients at the end of their lives, nor to cope with 
their own emotions in the face of the patient's death, to communicate with the dying patient or provide care to and cooperate with the patient's family. Similar results were obtained by Jors et al. [11] in a group of physicians and nurses working at cancer care centres. They reported a need for knowledge and skills in the field of basic palliative care, end-of-life patient communication, and cooperation/interaction with the dying patient's family. In the study by Mott et al. [6], medical students emphasised problems with communication with dying patients and pointed to difficulties associated with issues such as when to start a conversation, what tone of voice to use and what to expect as regards such conversations. On the other hand, the results of the study by Pawłowski et al. [14] on the impact of education in palliative medicine on medical students' perception of the care of dying patients, revealed that, after a week-long series of classes in palliative medicine, a change had occurred in opinions on how to solve patients' psychological, social and spiritual problems. Having obtained responses from 139 students before the classes and from 99 students after the classes, the authors noted statistically significant differences between how these areas were perceived by the respondents before and after said classes.

The available research results suggest that the consequences of the lack of preparation to provide professional care to dying patients are experienced not only by the patient and his/her relatives, but also by the medical staff whose representatives report discomfort being unable to offer relief to a suffering patient $[4,5]$. Therefore, the surveyed physicians and nurses emphasised the necessity to increase the hours of care of the dying patient, as well as diversifying the forms and methods of teaching these issues, stipulating an increase in the effectiveness of practical education [11].

\section{CONCLUSIONS}

1. Students of both majors are not confident as to the level of their preparation to provide care to patients at the end of their lives, nor about the extent to which their university education had introduced them to the specifics of care of a dying patient. The medical students exhibited higher statistical significance as compared to the nursing students $(\mathrm{p}<0.001)$.

2. The educational material taught as part of the curriculum prepared the students to take care of the dying patient's biological sphere, but did not provide them with preparation as regards care of the patient's mental and spiritual spheres, cooperation with and care of the patient's family, coping with emotions resulting from contact with death, and communicating with the patient. Knowledge deficits in these areas were reported by more medical than nursing students.

\section{REFERENCES}

1. Kotlińska-Lemieszek A, Łuczak J. Opieka Paliatywna/Hospicyjna/Medycyna Paliatywna. Now Lek. 2011;80(3):3-15.

2. Kübler-Ross E. Lęk przed śmiercią. In: E. Kübler-Ross. Rozmowy o śmierci i umieraniu. Poznań: Media Rodzina; 1979. p. 17-18.

3. Brien LA, Legault A, Tremblay N. Affective learning in end-of-life care education: the experience of nurse educators and students. Int J Palliat Nurs. 2008;14(12):610-4.

4. Shaw PA, Abbott MA. High-fidelity simulation: teaching end-of-life care Nurse Educ Today. 2017;49:8-11.

5. Barrere C, Durkin A. Finding the right words: the experience of new nurses after ELNEC education integration into a BSN curriculum. Medsurg Nurs. 2014;23(1):35-43.

6. Mott ML, Gorawara-Bhat R, Marschke M, Levine S. Medical students as hospice volunteers: reflections on an early experiential training program in end-of-life care education. J Palliat Med. 2014;17(6):696-700.

7. Anderson NE, Kent B, Owens RG. Experiencing patient death in clinical practice: Nurses' recollections of their earliest memorable patient death. Int J Nurs Stud. 2015;52:695-704

8. Dobrowolska B, Klukow J, Kręcisz K, et al. Kształcenie przeddyplomowe pielęgniarek i lekarzy a ich przygotowanie do pracy z pacjentem umierającym. Psychoonkologia. 2008;2:37-44.

9. Dobrowolska B, Cuber T, Ślusarska B, et al. Analysis of the nurses' and physicians' opinion regarding their end-of-life education. J Palliat Med. 2011;14(2):126-7.

10. Von Guten Ch, Mullan P, Nelesen RA, et al. Development and evaluation of a palliative medicine curriculum for third-year medical students. J Palliat Med. 2012;15(11):1198-206

11. Jors K, Seibel K, Bardenheuer H, et al. Education in end-of-life care: what do experienced professionals find important? J Cancer Educ. 2016;31:272-8.

12. Jeffers S. Nurse faculty perception of end-of-life education in the clinical setting: a phenomenological perspective. Nurse Educ Pract. 2014;14:455-60.

13. Ferguson R, Cosby P. Nursing students' attitudes and experiences toward end-of-life care: a mixed methods study using simulation. Clin Simul Nurs. 2017;13:343-6.

14. Pawłowski L, Buss T, Janiszewska J, et al. Wpływ kształcenia z zakresu medycyny paliatywnej na sposób postrzegania opieki paliatywnej przez studentów kierunku lekarskiego. Psychoonkologia. 2015;1:19-26.

\section{Corresponding author}

Dr hab. Beata Dobrowolska

Department of Basic Nursing and Medical Teaching, Medical University of Lublin 4-6 Staszica St., 20-081 Lublin, Poland

E-mail: bb.dobrowolska@gmail.com 